\title{
Barcode DNA length polymorphisms vs fatty acid profiling for adulteration detection in olive oil
}

\author{
Ali Tevfik Uncu ${ }^{1}$, Ayse Ozgur Uncu, Anne Frary, Sami Doganlar* \\ Izmir Institute of Technology, Department of Molecular Biology \& Genetics, Urla, Izmir 35430, Turkey
}

\section{A R T I C L E I N F O}

\section{Article history:}

Received 6 January 2016

Received in revised form 29 July 2016

Accepted 13 November 2016

Available online 14 November 2016

\section{Keywords:}

Capillary electrophoresis

Food authenticity

Food genomics

Traceability

\begin{abstract}
A B S T R A C T
The aim of this study was to compare the performance of a DNA-barcode assay with fatty acid profile analysis to authenticate the botanical origin of olive oil. To achieve this aim, we performed a PCRcapillary electrophoresis (PCR-CE) approach on olive oil: seed oil blends using the plastid trnL (UAA) intron barcode. In parallel to genomic analysis, we subjected the samples to gas chromatography analysis of fatty acid composition. While the PCR-CE assay proved equally efficient as gas chromatography analysis in detecting adulteration with soybean, palm, rapeseed, sunflower, sesame, cottonseed and peanut oils, it was superior to the widely utilized analytical chemistry approach in revealing the adulterant species and detecting small quantities of corn and safflower oils in olive oil. Moreover, the DNA-based test correctly identified all tested olive oil: hazelnut oil blends whereas it was not feasible to detect hazelnut oil adulteration through fatty acid profile analysis. Thus, the present research has shown the feasibility of a PCR-CE barcode assay to detect adulteration in olive oil.
\end{abstract}

(c) 2016 Elsevier Ltd. All rights reserved.

\section{Introduction}

Olive oil accounts for only $2 \%$ of the world's vegetable oil consumption, whereas seed oils (palm, soybean, canola, sunflower, cottonseed and peanut) are produced and consumed in much greater quantities (Costa, Mafra, \& Oliveira, 2012). However, there is a constantly increasing demand for olive oil especially in developed countries, due to a growing interest in natural, minimally processed food products rich in beneficial phytochemicals (Ulberth \& Buchgraber, 2000). Given its popularity as a healthy food and the significant price difference between cold-pressed extra virgin olive oils and refined seed oils, it is not surprising that olive oil is the most attractive target for adulteration of edible plant oils (Costa et al., 2012). Mixing olive oil with seed oils of lower economic value is a common fraudulent practice. In addition to a violation of consumer rights, adulteration with seed oils is a potential health threat, since the adulterant species may be allergenic (e.g. hazelnut, peanut, sesame, soybean) or, in extreme cases, toxic. Spanish toxic oil syndrome (TOS) highlights the importance of establishing the traceability of edible oils. In 1981, rapeseed oil

\footnotetext{
* Corresponding author.

E-mail addresses: atuncu@konya.edu.tr (A.T. Uncu), ozgurayseuncu@gmail.com (A.O. Uncu), annefrary@iyte.edu.tr (A. Frary), samidoganlar@iyte.edu.tr (S. Doganlar).

1 Present address: Necmettin Erbakan University, Department of Molecular Biology \& Genetics, Meram, Konya 42090, Turkey.
}

refined for industrial use was distributed as olive oil in the local markets of Madrid, leading to the outbreak of TOS. This multisystemic disease caused the deaths of over 350 people and resulted in permanent disorders in over 20 thousand affected individuals with more than $10 \%$ recorded as handicapped (WHO, 2004).

The authenticity of olive oils is usually determined using analytical chemistry methods that determine the fat phase constituents. The most commonly utilized approach is analysis of fatty acid composition by gas chromatography (GC) (Aparicio \& Aparicio-Ruiz, 2000; Ulberth \& Buchgraber, 2000; Yang, Ferro, Cavaco, \& Liang, 2013). Analysis of the intact triacylglycerol composition by reversed-phase high-performance liquid chromatography (HPLC) is a complementary/alternative approach to fatty acid profiling by GC (Aparicio \& Aparicio-Ruiz, 2000; Christopoulou, Lazaraki, Komaitis, \& Kaselimis, 2004; Jabeur et al., 2014; Ulberth \& Buchgraber, 2000). Analysis of minor constituents in the unsaponifiable fraction (e.g. tocopherols, sterols, hydrocarbons, alcohols) by chromatographic methods is also used to complement fatty acid analysis (Ulberth \& Buchgraber, 2000). Spectroscopic methods that require less complicated sample preparation steps than labor intensive chromatography are also gaining popularity for determination of edible oil authenticity (Costa et al., 2012). However, spectroscopic methods only give a rough idea of sample composition without any information about potential adulterants (Yang et al., 2013). 
All of the above mentioned chromatographic and spectroscopic analytical approaches rely on the assumption that the chemical composition of a blend will significantly deviate from that of olive oil due to a dramatic difference in the quantity of a given analyte between olive oil and the adulterant oil species. However, this assumption does not always hold especially for minor oil constituents (Ulberth \& Buchgraber, 2000). In addition, the composition of the abundant oil constituents (fat fraction) may also be statistically indistinguishable, as is the case for hazelnut oil and olive oil, which cannot be discriminated based on analytical chemistry approaches (Christopoulou et al., 2004; Woolfe \& Primrose, 2004). As a result, it is not surprising that hazelnut oil is the most commonly used seed oil for olive oil adulteration (Vietina, Agrimonti, \& Marmiroli, 2013). Moreover, the introduction of new oil seed varieties with desirable composition traits (e.g. high oleic acid content) obtained through breeding or genetic modification is unquestionably a challenge for the accurate assessment of the botanical origin of an oil sample. It is also important to note that fraudulent manufacturers are well aware of the chemical criteria used for authenticity assessment and take them into consideration when preparing blends to meet product specifications.

Food genomics relies on the hypothesis that remnant DNA in a food matrix can be recovered to serve as an analyte in food authenticity analyses (Agrimonti, Vietina, Pafundo, \& Marmiroli, 2011). As reviewed by Galimberti et al. (2013) and Madesis, Ganopoulos, Sakaridis, Argiriou, and Tsaftaris (2014), this hypothesis has led to the successful development of DNA-based food authenticity tests. Because DNA is not subject to environmental influence, it directly reflects the species/varietal composition in a food product. PCR-based techniques are often essential in order to amplify the residual DNA in a food matrix to useful quantities for downstream analyses. All genotyping platforms can be utilized in food genomic analyses. PCR amplicons of diagnostic DNA regions can be sequenced, or analyzed by agarose gel electrophoresis or highresolution capillary electrophoresis (CE), depending on the type of polymorphism (e.g. nucleotide substitutions, insertions/deletions) harbored by the target sequence. Techniques that involve simultaneous PCR amplification and genotyping, such as quantitative real time-PCR or high resolution melting analysis (HRM), can be coupled to PCR amplification.

DNA-based methods are increasingly employed to address the authenticity issues surrounding olive oil. The plastid genome is predominantly used as an analytical target in such work (Ganopoulos, Bazakos, Madesis, Kalaitzis, \& Tsaftaris, 2013; Kumar, Kahlon, \& Chaudhary, 2011; Li et al., 2012; Spaniolas, Bazakos, Awad, \& Kalaitzis, 2008; Spaniolas, Bazakos, Spano, Zoghby, \& Kalaitzis, 2010; Vietina et al., 2013; Wu et al., 2011; Zhang et al., 2012), as its high copy number in plant cells enables the recovery of a sufficient quality and quantity of DNA. Moreover, target amplification from a diverse range of taxa is achieved due to the conserved gene order and content of the plastid genome, which allow the design of universal primers (Uncu, Uncu, Celik, Doganlar, \& Frary, 2015). Wu et al. (2011) and Zhang et al. (2012) proposed a CE-SSCP (capillary electrophoresis single strand conformation polymorphism) assay conducted with amplicons from the $r b c L$ (ribulose-1,5-bisphosphate carboxylase/oxygenase) gene to detect adulteration of olive oil with seed oils. Species-specific probes were designed from a portion of the $r b c L$ gene in order to detect blends of olive oil with sesame, sunflower, soybean, rapeseed, peanut and corn oils through a suspension bead array assay (Li et al., 2012). High resolution melting analysis (HRM) of $r b c L$ amplicons also proved successful in detecting adulteration of olive oil with corn, sunflower, hazelnut and canola oils (Ganopoulos et al., 2013; Vietina et al., 2013). In other work, Kumar et al. (2011) introduced species-specific primers designed from the plastid intron maturase gene (matK) and the psbA-trnH intergenic spacer that enabled the detection of sunflower and canola oils in olive oil.

The present work is a comparative evaluation of the performance of a PCR-capillary electrophoresis (PCR-CE) barcode assay and GC analysis of fatty acid composition to authenticate the botanical origin of olive oil. Plastid trnL (UAA) intron was used as the DNA barcode in the study. Indeed, the plastid trnL (UAA) intron represents a remarkably useful DNA barcode for species discrimination in agro-food products. Primers that amplify the universal barcode region have been available since 1991 (Taberlet, Gielly, Pautou, \& Bouvet, 1991) and the universality of the trnL (UAA) intron was demonstrated in a diverse range of plant taxa (Gielly \& Taberlet, 1994; Taberlet et al., 1991; Taberlet et al., 2007). Moreover, the high rate of insertions/deletions (Gielly \& Taberlet, 1994) in the noncoding region can be translated into discriminative amplicon size separation assays that allow the identification of species composition in food products. Spaniolas, Bazakos, Awad, et al. (2008), Spaniolas, Bazakos, Spano, et al. (2010) were first to describe the potential of the trnL (UAA) intron to authenticate the botanical origin of plant oils. The authors demonstrated the presence of discriminative length polymorphisms in the barcode amplicon among oil crop species. Despite promising results, the utilization of the barcode assay was mainly demonstrated on DNA from tissue samples and it remains to be determined whether trnL (UAA) intron length polymorphisms allow detection of the presence of small quantities of seed oil in olive oil - seed oil admixtures. In the present work, a PCR-CE assay that allows botanical origin detection based on trnL (UAA) intron length polymorphisms was applied on a series of olive oil - seed oil admixtures for evaluation of the performance of the DNA-based assay to identify small quantities of seed oil in olive oil. Fatty acid profiling by GC analysis was performed in parallel in order to compare the performance of the DNA-based assay with the widely utilized analytical chemistry approach.

\section{Materials and methods}

\subsection{Plant oil samples and reference tissue}

Edible oil samples of 11 plant species were included in this work. Of the 11 edible oil types, two were unrefined (olive and hazelnut oils) and the remaining nine were refined (soybean, sesame, sunflower, rapeseed, corn, cottonseed, peanut, safflower and palm oils). The safflower oil used in the study was a 'high oleic' type. Olive oil (cv. Memecik) and reference leaf tissue from five different olive cultivars (Memecik, Gemlik, Ayvalik, Kilis Yaglik and Patos) were obtained from the Olive Research Institute (Izmir, Turkey). The olive oil was a product of 2013-2014. Cottonseed oil and reference cotton leaf tissue were obtained from the Cotton Research Station (Aydin, Turkey). Reference tissue samples of the remaining nine plant species were obtained from a private seed company (Agromar Seed, Bursa, Turkey) and respective oils were purchased from retail stores.

\subsection{DNA isolation}

DNA isolation from reference tissue samples was performed using a NucleoSpin Plant II Kit (Macherey Nagel, Duren, Germany) according to the manufacturer's instructions. For sample preparation, liquid nitrogen frozen tissue samples were ground using a mortar and pestle and $100 \mathrm{mg}$ ground tissue was used to isolate DNA. Admixtures of olive oil with the ten seed oil types were prepared in olive oil:seed oil ratios of $60: 40 \%, 75: 25 \%, 90: 10 \%$ and $95: 5 \%$. Blends of multiple oil types were prepared in ratios of 
40:30:30\%, 25:25:25:25\% and 90:5:5\%. DNA isolation from oil samples was performed using a Wizard ${ }^{\circledR}$ Magnetic DNA Purification System for Food (Promega Corp., Madison, WI, USA) according to the manufacturer's instructions. DNA extractions from reference tissue samples and their respective oils, as well as oil admixtures were performed in two replicates. DNA concentration was measured using a Qubit 2.0 Fluorometer (Life Technologies, Thermo Fisher Scientific Inc., Waltham, MA) with dsDNA BR Assay Kit (Life Technologies). DNA integrity was checked on a 1.5\% agarose gel. Ethidium bromide (Sigma-Aldrich, St. Louis, MO) dye was used for staining the gel. Thus, $1 \mu \mathrm{L}$ dye stock was added to each $100 \mathrm{ml}$ gel volume. DNA stock solutions $(5 \mu \mathrm{L})$ were mixed with $5 \mu \mathrm{L} \mathrm{ddH}_{2} \mathrm{O}$ and $2 \mu \mathrm{l} 6 \times$ DNA Loading Dye (Thermo Fisher Scientific Inc.) and loaded in a $1.5 \%$ agarose gel in $1 \mathrm{x}$ TAE buffer. DNA samples were then separated by a horizontal gel electrophoresis apparatus (Thermo Fisher Scientific Inc.) at $100 \mathrm{~V}$ for $1 \mathrm{~h}$. The gel was visualized using a Gel Doc ${ }^{\mathrm{TM}} \mathrm{XR}$ gel documentation system (Bio Rad Laboratories, Inc., Hercules, CA).

\subsection{PCR-Capillary electrophoresis (PCR-CE) barcode analysis}

Primers that amplify the plastid trnL (UAA) intron (Primers c \& d), were introduced by Taberlet et al. (1991). Primer sequences from the $5^{\prime}$ to $3^{\prime}$ direction are: Primer c: CGAAATCGGTAGACGCTACG, Primer d: GGGGATAGAGGGACTTGAAC. The plastid barcode was amplified in $20 \mu \mathrm{L}$ reaction mixtures containing $1 \times$ Colorless GoTaq Flexi PCR buffer, $1.5 \mathrm{mM} \mathrm{MgCl} 2,0.25 \mathrm{mM}$ of each deoxyribonucleotide triphosphate (dNTP) (Promega Corp.), 1 U GoTaq G2 Flexi DNA Polymerase (Promega Corp.), $0.25 \mu \mathrm{M}$ of each primer, and $5 \mathrm{ng}$ of reference tissue DNA or $5 \mathrm{ng}$ of oil DNA stock solution as template. Thermal cycling conditions consisted of one cycle of initial denaturation for $30 \mathrm{~s}$ at $95^{\circ} \mathrm{C}$, followed by 35 cycles $(40$ cycles for oil DNA) of $95^{\circ} \mathrm{C}$ for $10 \mathrm{~s}, 62^{\circ} \mathrm{C}$ for $20 \mathrm{~s}, 72{ }^{\circ} \mathrm{C}$ for $30 \mathrm{~s}$, with a final extension step of $2 \mathrm{~min}$ at $72{ }^{\circ} \mathrm{C}$. Sample loading to the Qiaxcel Advanced capillary electrophoresis system (Qiagen, Valencia, CA) did not involve a post-PCR labelling step, as readyto-use capillary cartridges filled with the staining dye - gel mixture are provided with Qiaxcel DNA High Resolution Kits (Qiagen). QX DNA Size Marker 50-800 bp, v2.0 (Qiagen) was used as the size standard, and QX Alignment Marker 15 bp/1000 bp (Qiagen) was used for size standard alignment. The high resolution run method OM800 was applied with a sample injection time of $10 \mathrm{~s}$. Barcode profiles were visualized using QIAxcel ScreenGel Software (Qiagen). PCR-CE barcode assay was performed in three replicates for each DNA sample and capillary electrophoresis runs were performed in two replicates.

\subsection{Gas chromatography (GC) analysis}

Oil samples were subjected to methyl esterification prior to injection to a GC device. Methyl esterification reactions were performed according to the European Official Methods of Analysis (EU Commission, 1991). Reaction solutions were centrifuged and the supernatant phase was collected and filtered prior to injection to the GC (Agilent 6890, Agilent Technologies, Santa Clara, CA) equipped with an autosampler (Agilent 7863 \& FID) and a split/ splitless injector. Column specifications were as follows: $100 \mathrm{~m}^{*} 0.25 \mathrm{~mm}$ ID, $0.2 \mu \mathrm{m}$ HP-88 (J\&W 112-88A7). Analytical conditions applied were: inlet temperature, $250{ }^{\circ} \mathrm{C}$; injection volume, $1 \mu \mathrm{L}$; split ratio, $1 / 50$; carrier gas, helium; head pressure, $2 \mathrm{ml} \mathrm{min}{ }^{-1}$ constant flow; oven temperature, $120^{\circ} \mathrm{C} 10$ for min, followed by an $3^{\circ} \mathrm{C} / \mathrm{min}$ increase up to $220^{\circ} \mathrm{C}, 220^{\circ} \mathrm{C}$ for $5 \mathrm{~min}$; detector temperature, $280^{\circ} \mathrm{C}$; detector gas, hydrogen: $40 \mathrm{ml} \mathrm{min}{ }^{-1}$, air: $450 \mathrm{ml} \mathrm{min}^{-1}$ helium make-up gas: $30 \mathrm{ml} \mathrm{min}^{-1}$. Chromatogram peaks of samples were compared to those of fatty acid methyl ester (FAME) standards based on their retention times.
All GC analyses were performed in two replicates. FAME percentage values obtained for each sample were analyzed in comparison with the Codex Alimentarius Standard for olive oils and olive pomace oils and Codex Alimentarius Standard for named vegetable oils.

\section{Results and discussion}

Genotypic and environmental influence on metabolic traits can cause wide variation among the compositions of olive oils from different geographical regions and harvest seasons (Boskou, Blekas, \& Tsimidiou, 2006), making it difficult to interpret data from chemical analyses to judge the authenticity of an olive oil sample. Moreover, mutational breeding and biotechnology has enabled the development of crop plants with unusual metabolic characteristics that may be absent in crops' germplasms (Uncu, Doganlar, \& Frary, 2013), complicating the traceability of plant oils. DNA barcodes that enable the discrimination of different plant species are valuable genomic tools to overcome difficulties in botanical origin authentication in plant oils.

In this work, we applied barcode DNA [plastid trnL (UAA) intron] PCR-CE analysis to olive oils adulterated with ten different seed oil species. We also subjected the samples to fatty acid profile analysis in order to assess the performance of the DNA-based assay compared to the widely accepted standard analytical test.

\subsection{PCR-CE analysis of reference tissue and oil samples}

The refining process is generally considered to reduce significantly the quantity of intact DNA in the end product (Costa et al., 2012). However, similar fluorometric DNA concentration measurements $(2-5 \mathrm{ng} / \mu \mathrm{L})$ were obtained for both unrefined and refined oil samples using equal quantities of starting material $(160 \mathrm{~g})$ for DNA extractions. In addition, we did not observe a correlation between barcode amplification efficiency and processing state of the oils under study (Fig. 1).

The plastid barcode was amplified using DNA from the reference tissue of 11 plant species and their corresponding oils. All 11 species displayed distinctive barcode fragments with no two species yielding fragments of identical size. Moreover, barcode size did not vary among the five olive cultivars, providing proof of the species specificity of trnL (UAA) intron length polymorphisms. Our results were in agreement with Spaniolas, Bazakos, Awad, et al. (2008), Spaniolas, Bazakos, Spano, et al. (2010), who demonstrated length polymorphisms of the barcode amplicon among olive, soybean, sunflower, sesame, cotton, corn and hazelnut. Barcode fragment length polymorphisms among olive and the remaining four oil seed species (palm, rapeseed, peanut and safflower) are shown for the first time in the present research. Barcode fragments amplified from the oil DNA of the 11 plant species matched those obtained from reference tissue samples, as expected (data not shown). The barcode amplicon size ranged between 388 (rapeseed) and $723 \mathrm{bp}$ (cotton) for the 11 species (Table 1). Olive barcode fragment size was 551 bp and the species with the closest barcode amplicon size to olive was sesame, which produced a barcode fragment of $560 \mathrm{bp}$ (Table 1). Nevertheless, a size difference of $9 \mathrm{bp}$ was far above the minimum fragment size resolution (2-3 bp) indicated for the CE system and therefore, was reproducibly detected in all replicate CE runs of the reference barcode amplicons.

\subsection{PCR-CE analysis and fatty acid profiling of plant oil admixtures}

PCR-CE analysis was applied to DNA from olive oil: seed oil admixtures. The ten seed oil types were present at 40,25, 10 and $5 \%$ in the admixture series. Barcode profiles obtained from the 
A

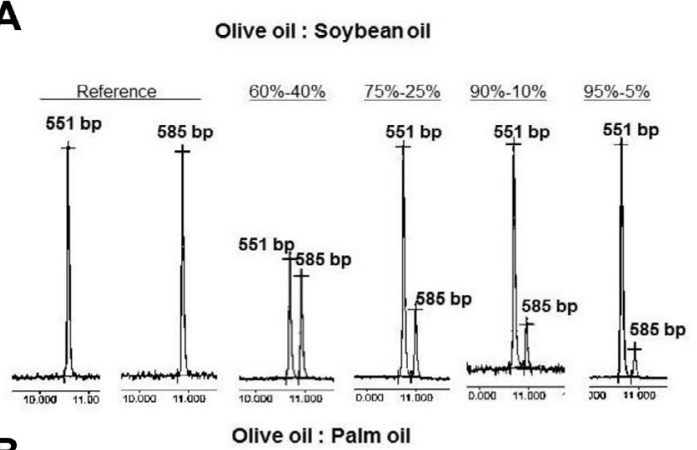

B

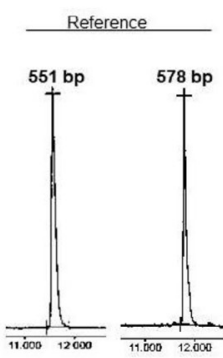

C
F

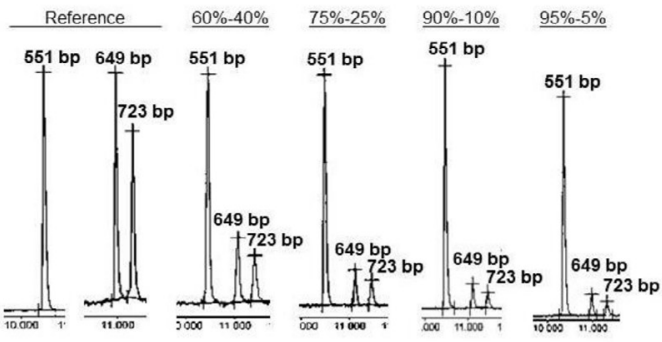

G

Olive oil : Peanut oil

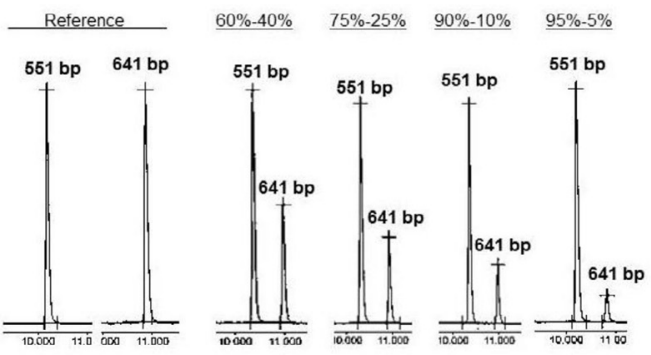

H

Olive oil : Corn oil

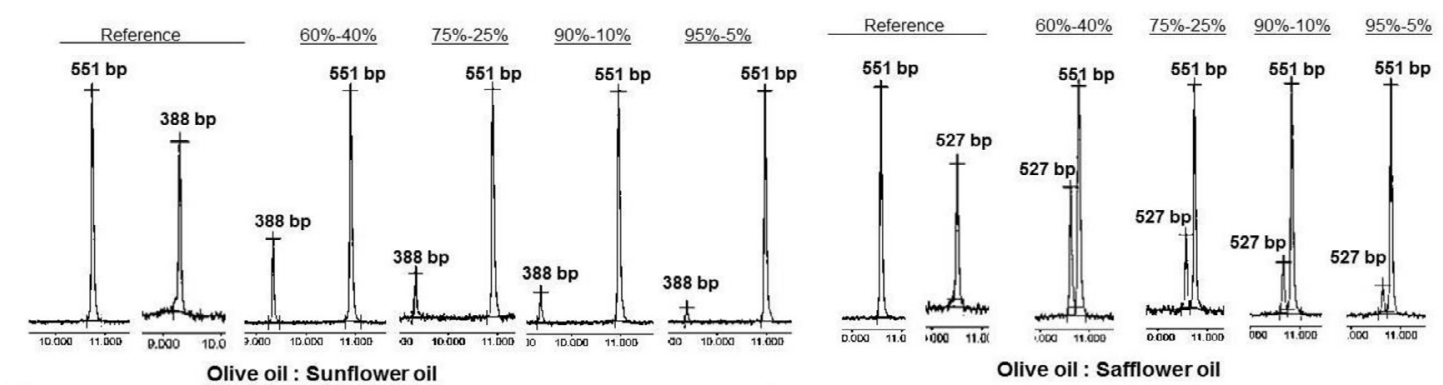

D

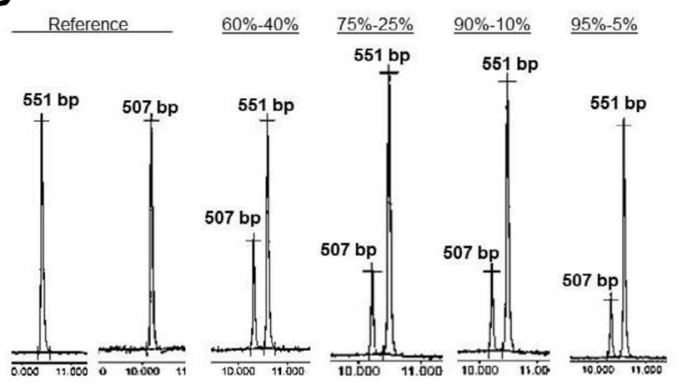

E

Olive oil : Sesame oil

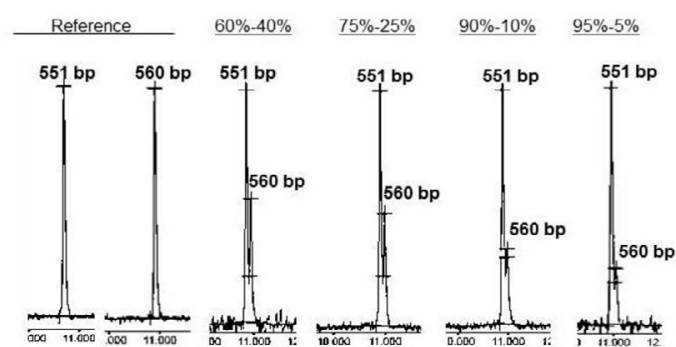

I

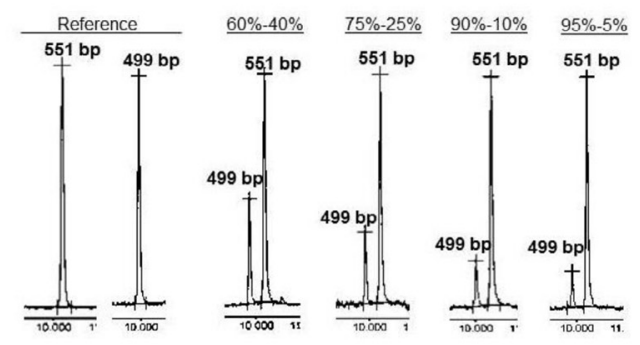

J

Olive oil : Hazelnut oil
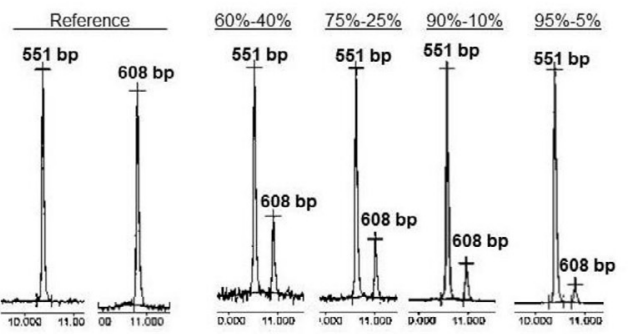

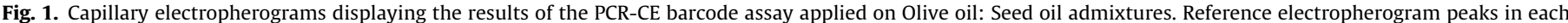

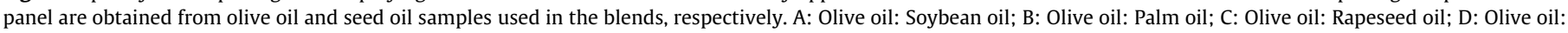
Sunflower oil; E: Olive oil: Sesame oil; F: Olive oil: Cottonseed oil; G: Olive oil: Peanut oil; H: Olive oil: Corn oil; I: Olive oil: Safflower oil; J: Olive oil: Hazelnut oil.

blends were analyzed in comparison with the profiles obtained from corresponding reference oil samples. The samples were also subjected to GC analysis in order to determine whether their fatty acid compositions deviated from that of olive oil as defined in the 
Table 1

Barcode [plastid trnL (UAA) intron] amplicon sizes of plant species used in this study.

\begin{tabular}{ll}
\hline Plant species (common name) & Barcode size \\
\hline Arachis hypogaea (peanut) & $641 \mathrm{bp}$ \\
Brassica napus (rapeseed) & $388 \mathrm{bp}$ \\
Carthamus tinctorius (safflower) & $499 \mathrm{bp}$ \\
Corylus avellana (hazelnut) & $608 \mathrm{bp}$ \\
Elaeis guineensis (oil palm) & $578 \mathrm{bp}$ \\
Glycine max (soybean) & $585 \mathrm{bp}$ \\
Gossypium hirsutum (cotton) & $649 \mathrm{bp} \& 723 \mathrm{bp}$ \\
Helianthus annuus (sunflower) & $507 \mathrm{bp}$ \\
Olea europaea (olive) & $551 \mathrm{bp}$ \\
Sesamum indicum (sesame) & $560 \mathrm{bp}$ \\
Zea mays (corn) & $527 \mathrm{bp}$ \\
\hline
\end{tabular}

Codex Alimentarius Standard. For this purpose, FAME percentage values obtained for each sample were compared to the fatty acid percentage ranges defined for olive oil in the codex.

Olive and soybean reference samples yielded barcode amplicons of $551 \mathrm{bp}$ and $585 \mathrm{bp}$, respectively (Table 1). When the PCRCE barcode assay was tested on olive oil: soybean oil admixtures, barcode profiles of the samples revealed two peaks, corresponding to olive and soybean-specific barcode fragments (Fig. 1-A). Similar results were obtained reproducibly for all admixing ratios, thus, the samples were correctly identified as admixtures of olive and soybean oils according to their PCR-CE barcode profiles. In a recent report on adulteration detection in olive oil with chromatographic techniques, linolenic acid (C18:3) was indicated as a determinant of fraud with soybean oil down to a limit of $5 \%$ (Jabeur et al., 2014). In our study, linolenic acid content of the olive oil: soybean oil admixtures ranged between 1.21 and $4.37 \%$. Thus, linolenic acid was the discriminative fatty acid to identify adulteration for all tested admixing ratios with values that exceeded the threshold of $1 \%$ defined for olive oil in the Codex Alimentarius Standard. Oleic (C18:1) and linoleic (C18:2) acid percentages were also out of the range for some olive oil: soybean oil blends. The range of oleic acid content defined for olive oil is between 55 and 83\%. Oleic acid content $(49.38 \%)$ was discriminative for the sample with the highest soybean oil content (40\%), but was not useful for identifying lower quantities of soybean oil adulteration, as it was consistently in the range defined for olive oil. Linoleic acid provided a higher sensitivity than oleic acid, with values that exceeded the upper limit for olive oil (21\%) in three out of four admixing ratios. Yet, linoleic acid content gradually declined from 32 to $12.9 \%$, not allowing the detection of adulteration in the sample spiked with $5 \%$ soybean oil. As a result, linolenic acid provided the highest sensitivity for the detection of soybean oil in olive oil. Apart from linolenic, linoleic and oleic acids, the relative content of the other fatty acid did not deviate from the pure olive oil standard ranges for any of the admixing ratios.

Oil palm reference tissue displayed a barcode amplicon size of 578 bp (Table 1). When the olive oil: palm oil admixtures were analyzed with the PCR-CE assay, the oil palm-specific barcode fragment was consistently detected alongside the olive-specific band for all four admixing ratios (Fig. 1-B). Thus, the barcode assay was efficient in detecting palm oil in olive oil down to a limit of $5 \%$. Results of the GC analysis revealed a myristic acid (C14:0) content that ranged between 0.12 and $0.41 \%$ for the olive oil: palm oil admixtures. Therefore, fatty acid profiles obtained for all four blends allowed their detection as admixtures according a myristic acid content above the standard $(<0.05 \%)$ defined for pure olive oil (Table 2). Except for myristic acid, methyl ester percentages were within the standard ranges for all other fatty acids in the chromatograms of the blends.
The rapeseed reference sample produced a barcode amplicon of 388 bp (Table 1). Both olive and rapeseed-specific barcode fragments were readily visible in the barcode electropherograms of their oils' admixtures (Fig. 1-C). As a result, the series of olive oil: rapeseed oil blends were all correctly identified as admixtures using the PCR-CE barcode analysis. GC analysis of the fatty acid composition also proved efficient in identifying adulteration in the samples. Erucic acid (C22:1) is normally present in undetectable amounts in olive oil and indicated as a marker of rapeseed oil adulteration (Yang et al., 2013). In this study, with values that ranged between 1.2 and $2.4 \%$, erucic acid was the only fatty acid that allowed adulteration detection down to a limit of 5\%, enabling the detection of rapeseed oil in all of the tested samples (Table 2). The other fatty acid that could serve as an indicator of rapeseed oil adulteration was linolenic acid, with percentage values that ranged between 2.9 and 1.62 for admixing ratios $\geqslant 10 \%$. However, when the rapeseed oil content in the blend was as low as $5 \%$, linolenic acid did not allow adulteration detection as its relative content was below the threshold (1\%). Erucic and linolenic acid were the only fatty acids with methyl ester percentage values that deviated from the accepted ranges for pure olive oil.

The barcode amplicon size of sunflower was $507 \mathrm{bp}$ (Table 1). PCR-CE barcode analysis of olive oil: sunflower oil admixtures resulted in the reproducible detection of both olive and sunflower-specific barcode fragments for the four admixing ratios (Fig. 1-D). When the results of the GC analysis were analyzed, behenic acid (C22:0) content was above $0.2 \%$ (between 0.51 and $0.66 \%$ ), thus this fatty acid was useful for detecting impurity in the adulterated olive oil samples (Table 2). Linoleic acid also served as an indicator of adulteration, however, with a lower sensitivity, remaining in the accepted range when the relative content of sunflower oil in the blend was $5 \%$.

The size of the barcode fragment amplified from reference sesame tissue was $560 \mathrm{bp}$ (Table 1). The barcode size of sesame was the closest to that of olive among the oil seeds analyzed in this work. Nevertheless, a difference of nine bases was successfully resolved when the PCR-CE assay was applied on olive oil: sesame oil admixtures. The sesame-specific barcode fragment was reproducibly detected down to a limit of $5 \%$ in all replicate experiments (Fig. 1-E). Similarly, fatty acid profiles of the blends deviated from that of olive oil with a linoleic acid content that ranged between 21.6 and $29 \%$, which was consistently above the standard limit (3.5-21\%) defined for olive oil (Table 2). Linoleic acid was the sole fatty acid that could serve as an indicator of sesame oil adulteration in the fatty acid profiles of the admixture series.

Cotton was distinguished from the rest of the plant species included in this study with a two-fragment barcode profile (Table 1), which was detected consistently in replicate experiments with DNA from reference tissue and oil samples. The two cotton-specific amplicons of 649 and 723 bp were present in olive oil: cottonseed oil blends for all four admixing ratios (Fig. 1-F), enabling the detection of adulteration in the samples. In the fatty acid profiles of the samples, linoleic acid content ranged between 23.3 and $32 \%$. Linoleic acid was used as the indicator of adulteration, as it was the only fatty acid that consistently exceeded the accepted limits (3.5-21\%) for pure olive oil (Table 2). Oleic acid was also useful in adulteration detection with cottonseed oil, however, with a lower sensitivity, as its relative content was below the codex lower limit (55\%) for only the higher admixing ratios of 40 (oleic acid methyl ester percentage: 45\%) and 25\% (oleic acid methyl ester percentage: 53\%). Except for linoleic and oleic acids, methyl ester percentages of all other fatty acids were within the accepted standards for all of the admixing ratios. 
Table 2

Performance of the PCR-CE assay and fatty acid profile analysis to detect olive oil: seed oil admixtures.

\begin{tabular}{|c|c|c|c|c|c|c|}
\hline Admixture type & Analysis method & $(60: 40 \%)$ & $(75: 25 \%)$ & $(90: 10 \%)$ & $(95: 5 \%)$ & Discriminative fatty acid \\
\hline \multirow[t]{2}{*}{ Olive oil: Soybean oil } & GC & $\mathrm{D}$ & $\mathrm{D}$ & $\mathrm{D}$ & $\mathrm{D}$ & Linolenic (C18:3) \\
\hline & PCR-CE & $\mathrm{D}$ & $\mathrm{D}$ & $\mathrm{D}$ & $\mathrm{D}$ & \\
\hline \multirow[t]{2}{*}{ Olive oil: Palm oil } & GC & $\mathrm{D}$ & $\mathrm{D}$ & $\mathrm{D}$ & $\mathrm{D}$ & Myristic (C14:0) \\
\hline & PCR-CE & $\mathrm{D}$ & $\mathrm{D}$ & $\mathrm{D}$ & $\mathrm{D}$ & \\
\hline \multirow[t]{2}{*}{ Olive oil: Rapeseed oil } & GC & $\mathrm{D}$ & $\mathrm{D}$ & $\mathrm{D}$ & $\mathrm{D}$ & Erucic (C22:1) \\
\hline & PCR-CE & $\mathrm{D}$ & $\mathrm{D}$ & $\mathrm{D}$ & $\mathrm{D}$ & \\
\hline \multirow[t]{2}{*}{ Olive oil: Sunflower oil } & GC & $\mathrm{D}$ & $\mathrm{D}$ & $\mathrm{D}$ & $\mathrm{D}$ & Behenic (C22:0) \\
\hline & PCR-CE & $\mathrm{D}$ & $\mathrm{D}$ & $\mathrm{D}$ & $\mathrm{D}$ & \\
\hline \multirow{2}{*}{ Olive oil: Sesame oil } & GC & $\mathrm{D}$ & $\mathrm{D}$ & $\mathrm{D}$ & $\mathrm{D}$ & Linoleic (C18:2) \\
\hline & PCR-CE & $\mathrm{D}$ & $\mathrm{D}$ & $\mathrm{D}$ & $\mathrm{D}$ & \\
\hline \multirow[t]{2}{*}{ Olive oil: Cottonseed oil } & GC & $\mathrm{D}$ & $\mathrm{D}$ & $\mathrm{D}$ & $\mathrm{D}$ & Linoleic (C18:2) \\
\hline & PCR-CE & $\mathrm{D}$ & $\mathrm{D}$ & $\mathrm{D}$ & $\mathrm{D}$ & \\
\hline \multirow[t]{2}{*}{ Olive oil: Peanut oil } & GC & $\mathrm{D}$ & $\mathrm{D}$ & $\mathrm{D}$ & $\mathrm{D}$ & Behenic (C22:0) \\
\hline & PCR-CE & $\mathrm{D}$ & $\mathrm{D}$ & $\mathrm{D}$ & $\mathrm{D}$ & \\
\hline \multirow[t]{2}{*}{ Olive oil: Corn oil } & GC & $\mathrm{D}$ & $\mathrm{D}$ & $\mathrm{D}$ & ND & Behenic (C22:0) \\
\hline & PCR-CE & $\mathrm{D}$ & $\mathrm{D}$ & $\mathrm{D}$ & $\mathrm{D}$ & \\
\hline \multirow[t]{2}{*}{ Olive oil: Safflower oil } & GC & $\mathrm{D}$ & $\mathrm{D}$ & ND & ND & Behenic (C22:0) \\
\hline & PCR-CE & $\mathrm{D}$ & $\mathrm{D}$ & $\mathrm{D}$ & $\mathrm{D}$ & \\
\hline \multirow[t]{2}{*}{ Olive oil: Hazelnut oil } & GC & ND & ND & ND & ND & None \\
\hline & PCR-CE & $\mathrm{D}$ & $\mathrm{D}$ & $\mathrm{D}$ & $\mathrm{D}$ & \\
\hline
\end{tabular}

D: Admixture was detected; ND: Admixture was identified as pure olive oil.

Peanut reference tissue produced a barcode amplicon of $641 \mathrm{bp}$ (Table 1). When the PCR-CE assay was tested on a series of olive oil: peanut oil admixtures, both species-specific fragments were detectable for all four admixing ratios (Fig. 1-G). As a result, the PCR-CE barcode assay proved efficient in identifying peanut oil in olive oil down to a limit of $5 \%$. In the relevant literature, behenic acid is indicated as a parameter for detection of fraud with peanut oil (Christopoulou et al., 2004). Indeed, in this study, the relative content of no fatty acid other than behenic acid deviated from the standard ranges. Thus, behenic acid was the only fatty acid that allowed adulteration detection for all four admixing ratios with a relative content that ranged between 0.99 and $1.28 \%$. Because the threshold defined in the standard for pure olive oil is $\leqslant 0.2 \%$, it was feasible to identify adulteration in the samples based on their behenic acid content.

The barcode fragment size of the reference corn tissue sample was $527 \mathrm{bp}$ (Table 1 ). The corn-specific fragment was reproducibly detected alongside the olive-specific $551 \mathrm{bp}$ amplicon in the electropherograms of the blends for all four admixing ratios (Fig. 1$\mathrm{H}$ ), enabling the detection of corn oil down to a limit of $5 \%$. Based on the FAME percentages, two fatty acids (linoleic and behenic) proved useful for identifying corn oil in olive oil, yet, with a limited sensitivity such that linoleic and behenic acid contents exceeded the accepted limits only when the relative content of corn oil in the blends was $\geqslant 25$ and $10 \%$, respectively. Using behenic acid as the discriminatory fatty acid, samples adulterated with 40, 25 and $10 \%(\mathrm{w} / \mathrm{w})$ corn oil could be detected as admixtures based on behenic acid contents of $0.48,0.33$ and $0.22 \%$, respectively. However, behenic acid content of the 95:5\% (olive oil:corn oil) blend was below detectable levels, not exceeding the limit $(0.2 \%)$ defined for olive oil (Table 2). Because the fatty acid composition of the blend did not deviate from that of olive oil, fatty acid profile analysis did not prove useful for judging the authenticity of the sample.

The size of the barcode fragment amplified from safflower reference tissue was 499 bp (Table 1). The PCR-CE assay was successful in detecting both olive and safflower-specific barcode amplicons in all of the tested blends (Fig. 1-I). Using the results of the fatty acid profile analysis, it was feasible to identify samples that contained 40 and $25 \%$ of safflower oil as adulterated based on the measured behenic acid contents of 0.48 and $0.36 \%$, respectively. Moreover, the admixtures that contained 10 and $5 \%$ of safflower oil had relative contents of all fatty acids within the ranges defined for olive oil in the Codex Alimentarius Standard. Thus, fatty acid profile analysis did not enable adulteration detection when safflower oil contribution in the blends was $\leqslant 10 \%$. We attribute this result to the fact that a 'high oleic' type safflower oil sample was used in the study. According to the Codex Alimentarius Standard for named vegetable oils, the range of relative oleic acid (C18:1) content defined for safflower oil is $8.4-21.3 \%$, which is far below that defined for olive oil (55-83\%). Similarly, there is a dramatic difference between the relative linoleic acid (C18:2) contents of safflower (67.8-83.2\%) and olive (3.5-21\%) oils defined by the codex. Thus, it is reasonable to expect that deviations in the relative contents of the two aforementioned major fatty acids would enable the detection of fraud even when safflower oil is present in small quantities. On the other hand, oleic and linoleic acid ranges for 'high oleic' safflower oil are $70-83.7 \%$ and $9-19.9 \%$, respectively, which are within the ranges defined for olive oil. Therefore, oleic and linoleic acid profiles were not useful in the detection of safflower oil adulteration in olive oil. Furthermore, as the sole discriminative criterion, behenic acid did not serve as an indicator of fraud for admixing ratios $\leqslant 10 \%$.

Hazelnut reference tissue displayed a barcode fragment size of 608 bp (Table 1). PCR-CE barcode assay reproducibly detected olive and hazelnut-specific barcode fragments for all of the tested admixing ratios (Fig. 1-J), thereby correctly identifying the samples as blends of olive oil and hazelnut oil down to a limit of 5\%. Because it is difficult to detect hazelnut oil adulteration in olive oil based on compositional criteria (Christopoulou et al., 2004; Vietina et al., 2013; Woolfe \& Primrose, 2004), it was important to assess the comparative performance of the DNA-based assay against the widely accepted analytical method. According to the results of an extensive study to determine the effectiveness of fatty acid and triacylglycerol profiling for adulteration detection in olive oil, neither fatty acid nor triacylglycerol profile proved useful for the detection of fraud with hazelnut oil (Christopoulou et al., 2004). In our study, while PCR-CE analysis was consistent in detecting hazelnut oil adulteration in olive oil (Fig. 1-J), fatty acid profiles of the samples were all within the range defined for olive oil and no fatty acid proved useful as a parameter to detect hazelnut oil contribution in the admixtures (Table 2).

When applied on ten different series of adulterated olive oil samples, the PCR-CE assay proved successful in correctly identifying the species composition in all of the admixtures. Fatty acid profile analysis proved equally efficient as the DNA-based assay for the 
seven seed oil types (soybean, palm, rapeseed, sunflower, sesame, cottonseed and peanut), enabling adulteration detection for all of the admixing ratios applied. However, it was not as sensitive as the DNA-based assay for a subset of seed oil types (corn, safflower and hazelnut). Moreover, it is important to note that besides adulteration detection, DNA analysis revealed the exact species composition in the samples through a single-step assay that involved CE separation of the PCR amplicons.

The sensitivity of the DNA-based assay was further tested and confirmed on admixtures of three and four different plant oil species. A blend that contained olive (40\%), sesame (30\%) and rapeseed oils (30\%) was correctly identified as a mixture of the three species' oils based on the barcode profile obtained through PCR-CE analysis (Fig. 2-A). Sesame oil was specifically included in the blend, as the size of the sesame-specific barcode fragment was the closest to that of olive oil among the tested oil seed species (Table 1). Therefore, it was valuable to further confirm that olive and sesame-specific barcode fragments could be successfully resolved by a capillary electrophoresis device when present in a mixture of amplicons. Similarly, it was feasible to distinguish barcode fragments of four different botanical sources, when the PCR-CE assay was applied on a blend of four different oil types (olive, peanut, rapeseed and corn oils) (Fig. 2-B). In order to investigate whether small quantities of adulterants could be identified in admixtures of more than two different oils, a blend was prepared that contained olive, palm and rapeseed oils at ratios of 90,5 and $5 \%$, respectively. As a result, a three-fragment barcode profile was reproducibly obtained from the blend (Fig. 2-C) that matched the three respective species-specific barcode sizes (Table 1 ). Thus, the fact that the DNA-based assay could detect adulterant seed oils present at quantities as low as $5 \%$ in admixtures was reconfirmed.

Simultaneous separation of barcode amplicons from reference standards (olive oil and adulterant seed oil species) and admixtures allowed identification of the species composition of the samples according to their CE barcode profiles. Thus, in addition to the detection of fraud, one can accurately identify the botanical origin of the adulterant by employing reference samples of different seed oil species alongside an olive reference. This is not possible with fatty acid analysis as a fatty acid is chemically the same regardless of its botanical source. Therefore, detection of abnormal levels of a fatty acid does not reveal the exact source of adulteration. For example in the present study, behenic acid was the common indicator of adulteration with soybean, corn, peanut, sunflower and safflower oils. Similarly, high levels of linoleic acid could indicate contamination with either cotton or sesame seed oil.

In cases where the adulterant in olive oil was corn, safflower or hazelnut oil, fatty acid profile analysis was not as efficient as it was for the rest of the seed oil species. Indeed, hazelnut oil was not detected at all in any of the olive oil: hazelnut oil admixtures. This was an expected result given the similarity of the fatty acid profiles of olive and hazelnut oils. Fatty acid profiling also did not provide evidence to detect safflower and corn oils in olive oil when their relative contents in the blends were $\leqslant 10$ and $5 \%$, respectively. In parallel with the results obtained in this work, fatty acid profile was reported as a poor determinant of small quantities of corn and safflower oils in olive oil. As a result, triacylglycerol analysis is recommended for the detection of fraud with these seed oil species (Christopoulou et al., 2004). Thus, it is apparent that GC analysis of fatty acids may produce false negative results when certain seed oils such as hazelnut, corn and safflower are used as adulterants. As suggested by several authors, a combination of methods, namely fatty acid and triglyceride analyses by GC and HPLC is required (Christopoulou et al., 2004; Jabeur et al., 2014). Nevertheless, given the wide range of compositional parameters determined for olive oil (Boskou et al., 2006), the accuracy of adulteration detection based on chemical composition is questionable. Because authenticity of an oil sample is judged based on the defined limits for chemical components, fraud cannot be detected unless established limits are exceeded (Aparicio \& Aparicio-Ruiz, 2000). Indeed, experimental adulteration recipes with chemical compositions within the acceptable ranges for olive oil were reported in support of the abovementioned argument (Aparicio \& Aparicio-Ruiz, 2000). While the presence of seed oils in a fraudulent product can be masked by taking into consideration and mimicking olive oil composition, there is no method to hide the presence of DNA. Therefore, once a DNA-based test that is capable of detecting the presence of any plant material in a given sample is established, fraud can accurately be detected regardless of the chemical composition of the end product. Such assays require the utilization of DNA barcodes that are universal yet polymorphic among plant taxa. In the present work, length polymorphisms of the trnL (UAA) intron served well in correctly identifying the botanical origin of plant oil admixtures. The presence of an adulterant at a relative content as low as $5 \%$ could successfully be determined with the PCR-CE method, whereas, the performance of fatty acid profile analysis was species-dependent, failing to detect fraud when

\section{Plant Oil Admixtures}

A

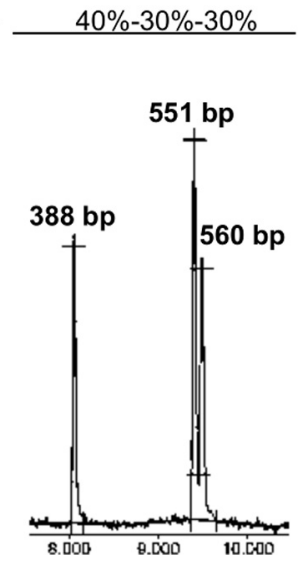

B

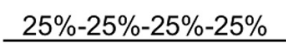

C $90 \%-5 \%-5 \%$

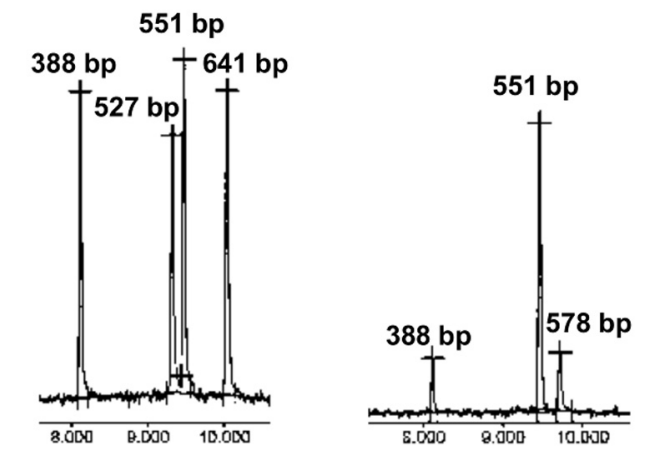

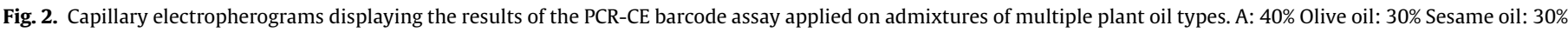
Rapeseed Oil; B: 25\% Olive oil: 25\% Peanut oil: 25\% Rapeseed oil: 25\% Corn oil; C: $90 \%$ Olive oil: $5 \%$ Palm oil: $5 \%$ Rapeseed oil. 
hazelnut oil was used as the adulterant (Table 2). Moreover, small quantities of some seed oil species, namely corn and safflower, could not be detected based on fatty acid analysis (Table 2). Thus, PCR-CE analysis of plastid trnL (UAA) intron proved superior over the widely accepted analytical chemistry approach in identifying adulteration in olive oil. Sensitivity to detect fraud as low as $5 \%$ regardless of the source is a good limit of detection as fraud is committed with economic motives, thus, it generally involves much higher proportions of adulterants (Pasqualone et al., 2016).

Interspecific length polymorphisms in the plastid trnL (UAA) intron were previously proposed for botanical origin authentication in plant oils (Spaniolas, Bazakos, Awad, et al., 2008; Spaniolas, Bazakos, Spano, et al., 2010). However, the applicability of a barcode amplicon size separation assay to discriminate species-specific fragments in oil blends was not investigated. The present research has shown the feasibility of this approach and demonstrated the performance of a PCR-CE barcode assay to detect small quantities of seed oil adulteration in olive oil. Moreover, this is the first time that a comparative approach was taken to evaluate the performance of a DNA-based assay with respect to that of chemical analysis.

\section{Conflict of interest}

The authors declare no conflict of interest.

\section{Acknowledgment}

This study was supported by Grant 1334 STZ 2012/1 from Republic of Turkey, Ministry of Science, Industry and Technology.

\section{References}

Agrimonti, C., Vietina, M., Pafundo, S., \& Marmiroli, N. (2011). The use of food genomics to ensure the traceability of olive oil. Trends in Food Science E Technology, 22, 237-244.

Aparicio, R., \& Aparicio-Ruiz, R. (2000). Authentication of vegetable oils by chromatographic techniques. Journal of Chromatography A, 881, 93-104.

Boskou, D., Blekas, G., \& Tsimidiou, M. (2006). Olive oil composition. In D. Boskou (Ed.), Olive oil chemistry and technology (pp. 41-72). Champaign, Illinois: AOCS Press.

Christopoulou, E., Lazaraki, M., Komaitis, M., \& Kaselimis, K. (2004). Effectiveness of determinations of fatty acids and triglycerides for the detection of adulteration of olive oils with vegetable oils. Food Chemistry, 84, 463-474.

Costa, J., Mafra, I., \& Oliveira, M. B. P. P. (2012). Advances in vegetable oil authentication by DNA-based markers. Trends in Food Science E Technology, 26, $43-55$.

European Union Commission. (1991). Regulation EEC 2568/91 on the characteristics of olive oil and olive-residue oil and on the relevant methods of analysis. Officia Journal of European Communities: Legislation, L248.
Galimberti, A., De Mattia, F., Losa, A., Bruni, I., Federici, S., Casiraghi, M., Martellos, S., et al. (2013). DNA barcoding as a new tool for food traceability. Food Research International, 50, 55-63.

Ganopoulos, I., Bazakos, C., Madesis, P., Kalaitzis, P., \& Tsaftaris, A. (2013). Barcode DNA high-resolution melting (Bar-HRM) analysis as a novel close-tubed and accurate tool for olive oil forensic use. Journal of the Science of Food and Agriculture, 93, 2281-2286.

Gielly, L., \& Taberlet, P. (1994). The use of chloroplast DNA to resolve plant phylogenies: noncoding versus rbcL sequences. Molecular Biology and Evolution, $11,769-777$.

Jabeur, H., Zribi, A., Makni, J., Rebai, A., Abdelhedi, R., \& Bouaziz, M. (2014). Detection of Chemlali extra-virgin olive oil adulteration mixed with soybean oil, corn oil, and sunflower oil by using GC and HPLC. Journal of Agricultural and Food Chemistry, 62, 4893-4904.

Kumar, S., Kahlon, T., \& Chaudhary, S. (2011). A rapid screening for adulterants in olive oil using DNA barcodes. Food Chemistry, 127, 1335-1341.

Li, Y., Wu, Y., Han, J., Wang, B., Ge, Y., \& Chen, Y. (2012). Species-specific identification of seven vegetable oils based on suspension bead array. Journal of Agricultural and Food Chemistry, 60, 2362-2367.

Madesis, P., Ganopoulos, I., Sakaridis, I., Argiriou, A., \& Tsaftaris, A. (2014). Advances of DNA-based methods for tracing the botanical origin of food products. Food Research International, 60, 163-172.

Pasqualone, A., Montemurro, C., di Rienzo, V., Summo, C., Paradiso, V. M., \& Caponio, F. (2016). Evolution and perspectives of cultivar identification and traceability from tree to oil and table olives by means of DNA markers. Journal of the Science of Food and Agriculture, 96, 3642-3657.

Spaniolas, S., Bazakos, C., Awad, M., \& Kalaitzis, P. (2008). Exploitation of the chloroplast trnL (UAA) intron polymorphisms for the authentication of plant oils by means of a Lab-on-a-Chip capillary electrophoresis system. Journal of Agricultural and Food Chemistry, 56, 6886-6891.

Spaniolas, S., Bazakos, C., Spano, T., Zoghby, C., \& Kalaitzis, P. (2010). The potential of plastid trnL (UAA) intron polymorphisms for the identification of the botanical origin of plant oils. Food Chemistry, 122, 850-856.

Taberlet, P., Coissac, E., Pompanon, F., Gielly, L., Miquel, C., Valentini, A., Vermat, T., et al. (2007). Power and limitations of the chloroplastic trnL (UAA) intron for plant DNA barcoding. Nucleic Acids Research, 35, e14.

Taberlet, P., Gielly, L., Pautou, G., \& Bouvet, J. (1991). Universal primers for amplification of three non-coding regions of chloroplast DNA. Plant Molecular Biology, 17, 1105-1109.

Ulberth, F., \& Buchgraber, M. (2000). Authenticity of fats and oils. European Journal of Lipid Science and Technology, 102, 687-694.

Uncu, A. O., Doganlar, S., \& Frary, A. (2013). Biotechnology for enhanced nutritional quality in plants. Critical Reviews in Plant Sciences, 32, 321-343.

Uncu, A. O., Uncu, A. T., Celik, I., Doganlar, S., \& Frary, A. (2015). A primer to molecular phylogenetic analysis in plants. Critical Reviews in Plant Sciences, 34, 454-468.

Vietina, M., Agrimonti, C. \& Marmiroli, N. (2013). Detection of plant oil DNA using high resolution melting (HRM) post PCR analysis: A tool for disclosure of olive oil adulteration. Food Chemistry, 141, 3820-3826.

Woolfe, M., \& Primrose, S. (2004). Food forensics: using DNA technology to combat misdescription and fraud. Trends in Biotechnology, 5, 222-226.

World Health Organization. (2004). Toxic Oil Syndrome, Ten Years of Progress.

Wu, Y., Zhang, H., Han, J., Wang, B., Wang, W., Ju, X., \& Chen, Y. (2011). PCR-CE-SSCP applied to detect cheap oil blended in olive oil. European Food Research and Technology, 233, 313-324.

Yang, Y., Ferro, M. D., Cavaco, I., \& Liang, Y. (2013). Detection and identification of extra virgin olive oil adulteration by GC-MS combined with chemometrics. Journal of Agricultural and Food Chemistry, 61, 3693-3702.

Zhang, H., Wu, Y., Li, Y., Wang, B., Han, J., Ju, X., \& Chen, Y. (2012). PCR-CE-SSCP used to authenticate edible oils. Food Control, 27, 322-329. 